\title{
Expulsion of inhaled foreign body and risk of endotracheal tube block
}

\begin{abstract}
Background: Aspiration of foreign body, especially pill aspiration, can occur to both outpatients and inpatients. Endotracheal tube block induced by an inhaled foreign body can be a life-threatening complication during resuscitation.

Case report: A 77 year-old female patient developed choking and coughing after taking herbal pills. Diagnosis of pill aspiration was suspected. Artificial coughing techniques were performed but were unsuccessful. Her respiratory failure became worse, and she was intubated and ventilated with a manual bag-valve resuscitator ("ambubag"). The aspirated pill was expelled through the endotracheal tube and the patient was extubated successfully.
\end{abstract}

Why should an emergency physician be aware of this? : The endotracheal tube in patients with foreign body aspiration should be observed closely because the inhaled foreign body may enter the tube with a risk of airway obstruction.

Keywords: foreign body, pill aspiration, spontaneous expulsion
Volume 2 Issue I - 2018

\author{
Lam Nguyen Ho \\ University of Medicine and Pharmacy at Ho Chi Minh City, \\ Vietnam
}

Correspondence: Lam Nguyen Ho, University of Medicine and Pharmacy at Ho Chi Minh City,Vietnam, Tel +84 90327568I, Emailbsholam1986@gmail.com

Received: December II, 2017 | Published: January 19, 2018

\section{Abbreviations: FB, foreign body; ET, endotracheal tube \\ Introduction}

Airway foreign body (FB) is a life-threatening condition not only in children but also in elderly patients. Many kinds of airway FB are documented, including seeds, food and other organic material. Pill aspiration is a distinct clinical entity estimated to comprise about $7 \%$ of airway foreign bodies. ${ }^{1}$ As it may occur to outpatients and inpatients, clinicians should be aware of it when managing patients in the clinic, emergency room and hospital ward. Bronchial FB may be embedded in bronchial wall with fibrotic change when chronic, lodged in an airway when acute, or migrate freely in the bronchial lumen. A free FB can move from bronchial tree into endotracheal tube (ET) causing ventilation obstruction..$^{2-4}$ Here we reported a case with inhaled pill expelled through the ET during ventilation with an ambubag.

\section{Case report}

A 77 year-old female patient was hospitalized more than three weeks with diagnoses of stage IV hepatocellular carcinoma and left pleural effusion. She took herbal pills (Figure 1) during the hospitalization to relieve pain relating to bone metastasis. On the twenty-fourth hospital night, she developed severe choking and coughing immediately after taking herbal pills. She was agitated but still conscious, and on clinical examination her blood pressure was $140 / 90 \mathrm{mmHg}$, pulse rate $120 / \mathrm{min}$, respiratory rate $30 / \mathrm{min}$, and peripheral capillary oxygen saturation $(\mathrm{SpO} 2) 86-88 \%$ with $3 \mathrm{~L} / \mathrm{min}$ of oxygen via nasal cannula. Accessory breath muscle use, wheezing and decreasing breath sound on the left chest were noted. Oxygen therapy via bag-valve mask at $10 \mathrm{~L} / \mathrm{min}$ was given. The diagnosis of pill aspiration was suspected. Therefore, back blows were performed, followed by three Heimlich maneuvers. Her condition did not improve, and her mental status and respiratory failure became worse. She was intubated with an 8-mm ET and ventilated with an ambu-bag. After compressing ambu-bag several times and noting increased resistance to manual ventilation, a pill appeared in the proximal portion of the ET and was removed immediately (Figure 2). Chest radiograph showed the end of tube into the right main bronchus and left lung atelectasis. The tube was withdrawn $4 \mathrm{~cm}$ and she could breathe spontaneously and comfortably through the tube. Bronchoscopy showed that there was no pill or its piece remaining in the airway and the patient was successfully extubated.

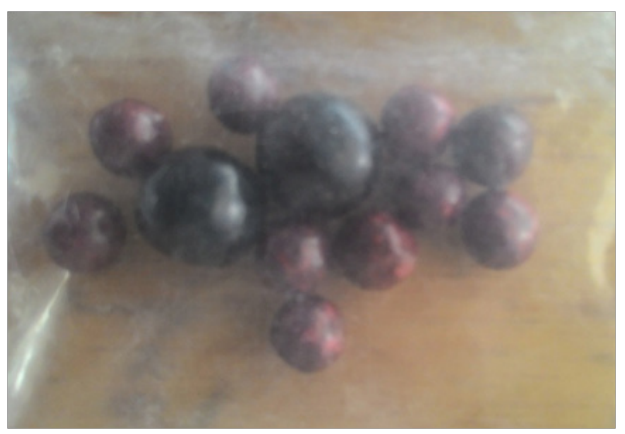

Figure I The original size of pills ranged from 7 to $12 \mathrm{~mm}$ and the component of pills were unknown.

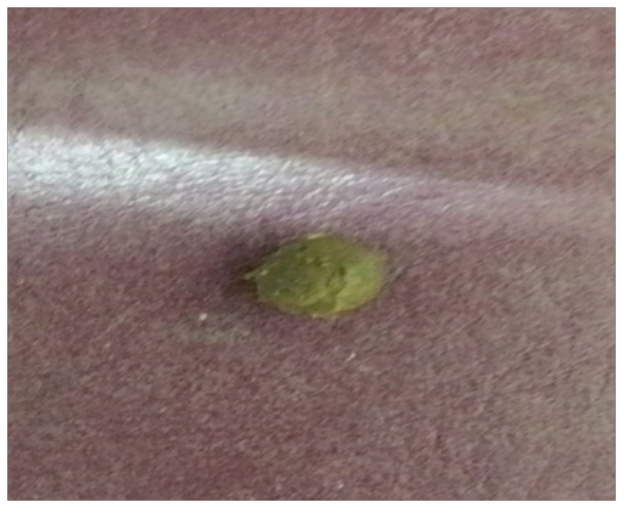

Figure 2 Shape of the aspirated pill was changed after the patient had taken it. 


\section{Discussion}

Published cases demonstrate the diversity of aspirated pills. This case described herbal pill aspiration in elder inpatient with a severe comorbidity. Elderly patients have the high risk of FB aspiration because of poor coordination of swallowing and significant comorbidities. ${ }^{6}$ Therefore; elderly inpatients should be supervised closely by their family or nurses while taking large pills.

Spontaneous expulsion of airway FB through oral route has been documented in the literature. ${ }^{7-9}$ In this case the aspirated pill was migrated into the ET and was expelled during ventilation with ambubag. Fortunately, this pill moved to the proximal ET and was retrieved easily. However, several published cases showed that bronchial FB can move into and block the ET. ${ }^{2-4}$ Therefore, close ET observation and prompt recognition of ET obstruction are essential for success of resuscitation.

\section{Why should an emergency physician be aware of this?}

Endotracheal intubation is an important procedure in managing patients with $\mathrm{FB}$ aspiration and acute respiratory failure. An FB in the airway can move into and block the ET. Early recognition of the ET obstruction induced by FB will be helpful in planning interventions and securing ventilation.

\section{Patient consent}

Written informed consent was obtained from the patient for publication of this case report and any accompanying images. A copy of the written consent is available for review by the Editor-in-Chief of this journal

\section{Acknowledgements}

I thank Professor Stephen Kantrow who assisted to edit English of this manuscript.

\section{Conflicts of interest}

The author declares no conflict of interest.

\section{References}

1. Mehta AC, Khemasuwan D. A foreign body of a different kind: pill aspiration. Ann Thorac Med. 2014;9(1):1-2.

2. Ehrenpreis MB, Oliverio_JR RM. Endotracheal tube obstruction secondary to oral preoperative medication. Anesth Analg. 1984;63(9):867-868.

3. Shalmovitz GZ, Halpern P. Delayed obstruction of endotracheal tubes by aspirated foreign bodies: report of two cases. Ann Emerg Med. 2004;43(5):630-633

4. Shahid M, Khan E. Difficult to Ventilate. Unusual Cause of Endotracheal Tube Obstruction. J Anesthe Clinic Res. 2011;2:131 p.

5. Kupeli E, Khemasuwan D, Tunsupon P, et al. Pills and the air passages: a continuum. Chest. 2015;147(1):242-50.

6. Folch E, Majid A. Foreign Body Aspiration in the Elderly Patient. Curr Geri Rep. 2015;4(2):192-201.

7. Hadi MA, Al Telmesani LM. Spontaneous expulsion of intrabronchial metallic foreign body: A case report. J Fam Community Med. 1997;4(2):77-79

8. Jaiswal AA, Garg AK. Spontaneous expulsion of foreign body (seewing machine needle) from right middle lobe bronchus - a rare case report. $J$ Clin Diagn Res. 2014;8(8):01KD-02KD.

9. Goyal A, Moha NVK, Mundra RK. Spontaneous expulsion of a bronchial foreign body. Otolaryngol-Head Neck Surgery. 2007;136:324-325. 